\title{
CRESCIMENTO E PRODUTIVIDADE DE POVOAMENTOS MONOESPECÍFICOS E MISTOS DE EUCALIPTO E ACÁCIA-NEGRA ${ }^{1}$
}

\author{
Márcio Viera², Mauro Valdir Schumacher², Edenilson Liberalesso ${ }^{2}$
}

\begin{abstract}
GROWTH AND YIELD IN MONOSPECIFIC AND MIXED

STANDS OF Eucalyptus urograndis AND Acacia mearnsii

Forest intercropping with nitrogen-fixing species can provide an increase in eucalyptus yield. The objective of this study was to evaluate growth and yield in monospecific and mixed stands of Eucalyptus urograndis and Acacia mearnsii, in Bagé, Rio Grande do Sul State, Brazil. Treatments were 100E (100\% eucalyptus), 100A (100\% black wattle), 50E:50A (50\% eucalyptus $+50 \%$ black wattle), 75E:25A (75\% eucalyptus + $25 \%$ black wattle), and 25E: $75 \mathrm{~A}$ ( $25 \%$ eucalyptus $+75 \%$ black wattle). The first evaluation was carried out at the age of 6 months (diameter at stem and total height) and the second at 18 months (diameter at breast height, total height, volume with bark, and leaf area index). The Eucalyptus urograndis and Acacia mearnsii diameter and total height growth, for both 6 and 18 months, did not differ among treatments. The total wood yield $\left(\mathrm{m}^{3} \mathrm{ha}^{-1}\right)$ was the same for cropping and intercropping, without any influence from other species. The mixed cropping system resulted in a greater number of individuals with higher diameters $(\mu+1 \mathrm{~s})$, when compared to the cropping system, offering the forester an opportunity to obtain multiple products from his/her forest, due to a greater assortment provided by the presence of the two species.
\end{abstract}

KEY-WORDS: Eucalyptus urophylla S. T. Blake x Eucalyptus grandis Hill ex Maiden; Acacia mearnsii De Wild; forest intercropping; species interaction.

\section{INTRODUÇÃO}

O interplantio de espécies leguminosas fixadoras de nitrogênio com eucalipto pode aumentar o crescimento e a produtividade dos povoamentos. Isto decorre do fato de que as espécies da família Fabaceae (leguminosae) provocam melhora nos atributos químicos do solo, por meio de uma maior disponibilização de nitrogênio ao sistema, primeiramente pela morte e decomposição de raízes finas e conseguinte depo-

\section{RESUMO}

O interplantio de leguminosas arbóreas fixadoras de nitrogênio pode proporcionar incremento na produtividade das plantas de eucalipto. Objetivou-se, com este estudo, avaliar o crescimento e a produtividade de povoamentos monoespecíficos e mistos de Eucalyptus urograndis e Acacia mearnsii, no município de Bagé (RS). Os tratamentos estudados foram os seguintes: 100E (100\% de eucalipto), 100A (100\% de acácianegra), 50E:50A (50\% de eucalipto $+50 \%$ de acácia-negra), $75 \%$ E:25\%A (75\% de eucalipto $+25 \%$ de acácia-negra) e 25E: $75 \mathrm{~A}(25 \%$ de eucalipto $+75 \%$ de acácia-negra). A primeira avaliação do crescimento foi realizada aos 6 meses de idade (aferição do diâmetro do coleto e altura total) e a segunda aos 18 meses (diâmetro à altura do peito, altura total, volume com casca e índice de área foliar). $\mathrm{O}$ crescimento em diâmetro e a altura total do Eucalyptus urograndis e da Acacia mearnsii, tanto aos 6 como aos 18 meses, não diferiram entre os tratamentos. A produção total de madeira $\left(\mathrm{m}^{3} \mathrm{ha}^{-1}\right)$ foi a mesma no consórcio e no monocultivo, não havendo influência da presença de outra espécie. O cultivo misto resultou em maior número de indivíduos com diâmetros superiores $(\mu+1 \mathrm{~s})$, em relação aos monocultivos, proporcionando, ao silvicultor, a obtenção de produtos múltiplos de sua floresta, devido a um maior sortimento proporcionado pela presença de duas espécies florestais.

PALAVRAS-CHAVE: Eucalyptus urophylla S. T. Blake x Eucalyptus grandis Hill ex Maiden; Acacia mearnsii De Wild; consórcio florestal; interações entre espécies.

sição e decomposição da serapilheira (Vezzani 1997, Forrester et al. 2006a). Além disto, plantios consorciados podem proporcionar melhorias na estrutura do solo, devido à diferenciação na ocupação do solo, entre os sistemas radiculares; aumentar o teor de matéria orgânica, em consequência da formação de uma camada de serapilheira composta por maior diversidade de agentes decompositores; e promover condições ecofisiológicas favoráveis ao crescimento das árvores (Gama-Rodrigues 1997, Mendonça et al. 2008).

1. Trabalho recebido em ago./2010 e aceito para publicação em set./2011 (nº registro: PAT 10760/ DOI: 10.5216/pat.v41i3.10760).

2. Universidade Federal de Santa Maria, Departamento de Ciências Florestais, Santa Maria, RS, Brasil.

E-mails: vieraflorestal@yahoo.com.br,mvschumacher@gmail.com, edliberalesso@yahoo.com.br. 
Forrester et al. (2005) encontraram predomínio de interações positivas (facilitação e redução competitiva), em detrimento de negativas (competitividade), em plantio misto de Eucalyptus globulus e Acacia mearnsii, evidenciado pelo maior crescimento em altura, diâmetro, incremento em biomassa acima do solo e volume de madeira, em tratamentos com misturas das espécies. Isto demonstra, segundo os autores supracitados, o benefício de seleção de espécies capazes de fixar uma quantidade significativa de $\mathrm{N}$ e torná-lo prontamente disponível, com a decomposição da serapilheira e das raízes finas.

Vários estudos têm demonstrado que o plantio misto de eucalipto e leguminosas arbóreas resulta em incremento na produtividade das espécies envolvidas. Isto foi verificado no consórcio de Eucalyptus globulus com Acacia mearnsii (Khanna 1997, Bauhus et al. 2000, Forrester et al. 2004, Forrester et al. 2005, Forrester et al. 2006b), Eucalyptus saligna com Albizia falcataria (Binkley et al. 2000), Eucalyptus saligna com Falcataria molucna (Binkley et al. 2003), Eucalyptus grandis com Acacia mangium (Laclau et al. 2008), eucalipto com leguminosas arbóreas nativas (Coêlho 2006) e Eucalyptus camaldulensis com Acacia mangium (Schiavo et al. 2004). No entanto, existem outros estudos, nos quais se observou pouca ou nenhuma vantagem no crescimento das espécies (Jesus \& Dias 1988, Debell et al. 1997), onde elas apresentaram crescimento similar em monocultivo e em plantio misto e, até mesmo, prejuízo no crescimento de uma ou outra espécie florestal (Parrotta 1999, Hunt et al. 2006), provocado pela concorrência interespecífica.

Mas é difícil predizer a combinação de espécies e sítios que poderiam apresentar esses benefícios ou restrições ao crescimento, devido às características intrínsecas que cada espécie apresenta, nos diferentes sítios. Dessa forma, o plantio misto bem-sucedido é aquele em que a produtividade das espécies envolvidas aumenta, em relação ao seu monocultivo, reforçando a ideia de que este aumento de produtividade, em plantios mistos, se deve, principalmente, à relativamente maior taxa de ciclagem de nutrientes. Por isto, é importante selecionar espécies fixadoras de nitrogênio com fácil decomposição de serapilheira e alta taxa de ciclagem de nutrientes, assim como alta capacidade de fixação de $\mathrm{N}_{2}$ (Forrester et al. 2006c).

Uma vasta revisão de literatura sobre plantios mistos, realizada por Forrester et al. (2006c) e Piotto (2008), revelou não somente que, em geral, as mis- turas de espécies florestais são mais produtivas do que as monoculturas, mas, também, que os plantios mistos podem ter importante papel na satisfação de necessidades econômicas, por meio de rotações sortidas, e, ainda, fornecer benefícios ecológicos.

Várias outras questões ainda necessitam ser respondidas, como, por exemplo, se as intervenções silviculturais, tais como desrama, desbaste e fertilização, podem influenciar na dinâmica de fixação de nitrogênio, com a idade do povoamento. Também, não se sabe se aumentos de produção resultarão em aumentos na produtividade total - acima e abaixo do solo (Forrester et al. 2005), além de ser difícil predizer a combinação de espécies e sítios que poderiam apresentar benefícios (Forrester et al. 2006c).

Dessa forma, objetivou-se, com este trabalho, avaliar o crescimento e a produtividade de plantios monoespecíficos e mistos de Eucalyptus urograndis e Acacia mearnsii, na região de Bagé (RS).

\section{MATERIAL E MÉTODOS}

O estudo foi realizado em área experimental localizada no município de Bagé, no extremo sul do Estado do Rio Grande do Sul ( $31^{\circ} 14^{\prime} 43^{\prime \prime} \mathrm{S}, 54^{\circ} 04^{\prime} 55^{\prime \prime} \mathrm{W}$ e altitude média de $242 \mathrm{~m}$ ), em 2008/2009.

Segundo a classificação climática de Köppen, o tipo de clima predominante é o Cfa (temperado úmido, com verão quente). A precipitação média anual na região é de $1.364 \mathrm{~mm}$ e a temperatura média anual de, aproximadamente, $17,5^{\circ} \mathrm{C}$, sendo a média das máximas de $23,5^{\circ} \mathrm{C}$ e a das mínimas de $12,3^{\circ} \mathrm{C}$. Ocorrem, em média, 21 geadas por ano. A insolação média anual é de 2.444 horas, com umidade relativa média anual de 78\% (Moreno 1961).

O solo da área experimental é classificado como Argissolo Vermelho-Amarelo distrófico latossólico (Streck et al. 2008). Devido à baixa fertilidade natural destes solos (distróficos), forte acidez e alta saturação por alumínio, eles exigem investimentos em corretivos, fertilizantes e sistemas de manejo, para alcançar rendimentos satisfatórios. Dessa forma, os investimentos são maiores nestes solos arenosos, com baixo teor de argila e matéria orgânica, e que possuem saturação por bases e capacidade de troca de cátions baixa, junto a elevado teor de alumínio extraível (Streck et al. 2008).

$\mathrm{O}$ delineamento experimental adotado foi o de blocos ao acaso, com cinco tratamentos e três repetições. Os tratamentos utilizados foram: 100E 
(100\% de eucalipto), 100A (100\% de acácia-negra), 50E:50A ( $50 \%$ de eucalipto $+50 \%$ de acácia-negra), $75 \mathrm{E}: 25 \mathrm{~A}(75 \%$ de eucalipto $+25 \%$ de acácia-negra $)$ e 25E: $75 \mathrm{~A}(25 \%$ de eucalipto $+75 \%$ de acácia-negra) .

Devido à área experimental ser utilizada para a formação de sistemas agrossilviculturais, durante os seis meses iniciais, após o plantio florestal, o espaçamento utilizado foi de $4,0 \mathrm{~m} \times 1,5 \mathrm{~m}$. A área total de cada parcela foi de $1.224 \mathrm{~m}^{2}(25,5 \mathrm{mx} 48,0 \mathrm{~m})$. Foram deixados 6 metros entre tratamentos e entre blocos, para não ocorrer interferência de um tratamento sobre o outro e para sua divisão. Para as avaliações e/ou mensurações, considerou-se bordadura dupla, para isolar possíveis interferências externas, nos dados obtidos nos tratamentos.

Para a implantação das espécies florestais, foi realizada subsolagem, à profundidade média de $0,50 \mathrm{~m}$, na linha de plantio, com subsolador de uma haste. Concomitantemente a esta operação, foram aplicados $300 \mathrm{~kg} \mathrm{ha}^{-1}$ da fórmula 06-30-06 + 7\% de $\mathrm{Ca}+6 \%$ de $\mathrm{S}+0,1 \%$ de $\mathrm{B}+0,5 \%$ de $\mathrm{Cu}$, na linha de plantio. Em seguida, foram realizadas duas gradagens na linha de plantio, devido à intensa presença de gramíneas.

O plantio das mudas de eucalipto e acácia-negra foi realizado manualmente, em novembro de 2007. Na ocasião do plantio, como também antes dele, realizou-se o controle de formigas, com formicida granulado, sendo aplicados, em porta-iscas, $6 \mathrm{~g}$ de formicida, a cada $16 \mathrm{~m}^{2}$. Para o controle de plantas daninhas, foi realizado coroamento manual, em um raio de 0,50 m no entorno das plantas, aos 2 meses após o plantio, além da aplicação de herbicidas à base do princípio ativo glifosato, no restante da linha de plantio.

Realizou-se a avaliação de crescimento em diâmetro do coleto (Dc) (aos 6 meses de idade), diâmetro à altura do peito (DAP) (aos 18 meses) e altura total (aos 6 e 18 meses). As aferições de diâmetro foram realizadas com auxílio de paquímetro (Dc) e fita diamétrica (DAP). A altura total foi determinada com régua dendrométrica (aos 6 meses) e hipsômetro vertex (aos 18 meses).

A partir do diâmetro médio à altura do peito de cada repetição dos tratamentos 100E (100\% eucalipto), 100A (100\% acácia-negra) e 50E:50A (50\% eucalipto $+50 \%$ acácia-negra), aos 18 meses de idade do povoamento, escolheu-se uma árvore a ser abatida, para a determinação do volume com casca. $\mathrm{O}$ volume com casca foi determinado por meio de cubagem rigorosa, segundo método desenvolvido por Smalian e descrito por Soares et al. (2006), e sua extrapolação foi baseada no número de árvores por hectare, para cada tratamento.

$\mathrm{Na}$ determinação do índice de área foliar (IAF), utilizaram-se os mesmos indivíduos nos quais se realizou a cubagem. Para a obtenção da área foliar, foi necessária a amostragem de folhas de toda a parte aérea da planta (aproximadamente $40 \mathrm{~g}$ de massa úmida). Efetuou-se este procedimento de amostragem para cada árvore média abatida. Posteriormente, de cada uma delas, foram obtidas imagens digitais, após terem sido prensadas entre uma superfície de cor branca e um vidro transparente. Posteriormente à obtenção das fotos digitais, com auxílio de câmera digital (7.0 megapixels), apoiada em uma estrutura metálica com altura fixa de $0,5 \mathrm{~m}$, as imagens foram processadas com o auxílio do software Image Toll for Windows version $3.00^{\circ}$ (UTHSCSA 2002), que determina a área das folhas. Dessa forma, com base na biomassa úmida das amostras, extrapolou-se a área foliar para biomassa total de folhas, determinada em $\mathrm{m}^{2}$ árvore ${ }^{-1}$. Efetuando-se a divisão desta área foliar pela área de superfície correspondente ao espaçamento, obteve-se o IAF.

Aplicou-se o teste de homogeneidade de variâncias de Bartlett e de normalidade dos erros de Lilliefors aos resultados, para verificação de sua validação, pelos pressupostos da análise de variância. Resultados que não atenderam aos pressupostos foram transformados aplicando-se a raiz quadrada e, em seguida, analisados. As análises estatísticas foram realizadas com o auxílio do programa estatístico ASSISTAT, versão 7.5 beta (Silva 2008), e, para a separação dos contrastes de médias, utilizou-se o teste Tukey $(5 \%)$.

\section{RESULTADOS E DISCUSSÃO}

O crescimento em diâmetro do Eucalyptus urograndis e da Acacia mearnsii, tanto aos 6 quanto aos 18 meses de idade, não diferiu significativamente $(p>0,05)$ entre os tratamentos, evidenciando apenas uma tendência de aumento em diâmetro à altura do peito, no tratamento 50E:50A (50\% de eucalipto + $50 \%$ de acácia-negra), em relação aos plantios puros (100E - 100\% eucalipto e 100A - 100\% acácia-negra) (Figura 1). Realizando-se comparação entre as espécies, o Eucalyptus urograndis apresentou maior diâmetro de coleto $(\mathrm{p}<0,05)$, em relação à Acacia 


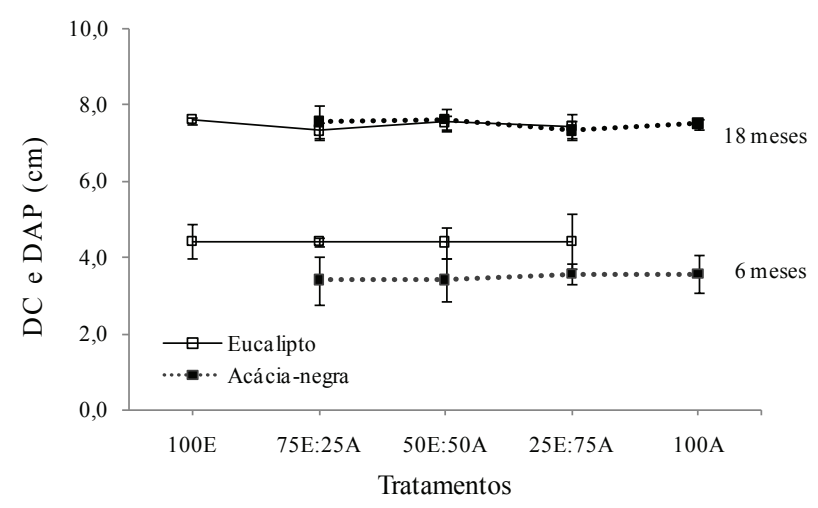

Figura 1. Crescimento em diâmetro do coleto (6 meses de idade) e diâmetro à altura do peito (18 meses), em povoamentos monoespecíficos e mistos de Eucalyptus urograndis e Acacia mearnsii (Bagé, RS, 2008/2009). As barras verticais correspondem ao desvio padrão da média.

mearnsii, em todos os tratamentos, fato não ocorrido aos 18 meses de idade, quando o diâmetro à altura do peito foi estatisticamente igual ( $\mathrm{p}>0,05)$.

Dessa forma, não se verificaram interações positivas ou negativas interespecíficas ou intraespecíficas que favorecessem o crescimento em Dc (6 meses de idade) e DAP (18 meses), em plantios monoespecíficos e mistos de Eucalyptus urograndis e Acacia mearnsii. Situação idêntica a esta foi verificada por Kleinpaul (2008), com os mesmos arranjos de espécies deste estudo, em que o crescimento em diâmetro do colo das árvores, aos 10 meses de idade $(100 \mathrm{E}=3,11 \mathrm{~cm} ; 100 \mathrm{~A}=4,25 ; 50 \mathrm{E}: 50 \mathrm{~A}(\mathrm{E})=2,92$; $50 \mathrm{E}: 50 \mathrm{~A}(\mathrm{~A})=3,31 ; 75 \mathrm{E}: 25 \mathrm{~A}(\mathrm{E})=3,15 ; 75 \mathrm{E}: 25 \mathrm{~A}(\mathrm{~A})=$ $3,64 ; 25 \mathrm{E}: 75 \mathrm{~A}(\mathrm{E})=3,21$ e $25 \mathrm{E}: 75 \mathrm{~A}(\mathrm{~A})=4,40)$, não foi influenciado pela presença ou ausência de outra espécie florestal em consórcio.

Neste mesmo sentido, Silva (2007), avaliando plantios monoespecíficos e mistos de Eucalyptus grandis e Acacia mangium, com 29 meses de idade, verificou que o Eucalyptus grandis, no plantio misto, não apresentou diminuição ou aumento no crescimento em área basal, em relação ao seu monocultivo. Já Forrester et al. (2004) observaram que o crescimento inicial (primeiros anos de idade) da acácia-negra, em plantios mistos, é maior do que o do eucalipto. Eles observaram que os diâmetros de Eucalyptus globulus foram significativamente maiores em consórcios do que em monoculturas, aos 4 anos de idade, e estas diferenças aumentaram, com o tempo, até os 11 anos de idade.

Os plantios monoespecíficos contêm grande variação de diâmetros, enquanto os consórcios possuem maior proporção de árvores em classes de diâmetro superiores (Figura 2). Para efeito comparativo, neste estudo, definiu-se como árvore de diâmetro superior aquela que tinha diâmetro à altura do peito superior à média mais um desvio-padrão. Para o Eucalyptus urograndis, o diâmetro é superior a $8,4 \mathrm{~cm}$ e, para a Acacia mearnsii, superior a $8,7 \mathrm{~cm}$, aos 18 meses de idade.

Para o Eucalyptus urograndis e, principalmente, para a Acacia mearnsii, há diminuição da relação entre o número de árvores por hectare com diâmetro superior, à proporção em que aumenta a percentagem de presença da outra espécie em consórcio. O mesmo foi verificado por Forrester et al. (2004), onde, para a Acacia mearnsii, ocorreu aumento significativo no número de árvores de diâmetro superior, com o aumento da proporção de Eucalyptus globulus, mas, para este, não foi observado aumento significativo no número de árvores com diâmetro superior.

O crescimento em altura do Eucalyptus urograndis e da Acacia mearnsii, tanto aos 6 quanto aos 18 meses de idade, não diferiu significativamente $(p>0,05)$ entre os tratamentos (Figura 3). Este mesmo comportamento foi verificado por Kleinpaul
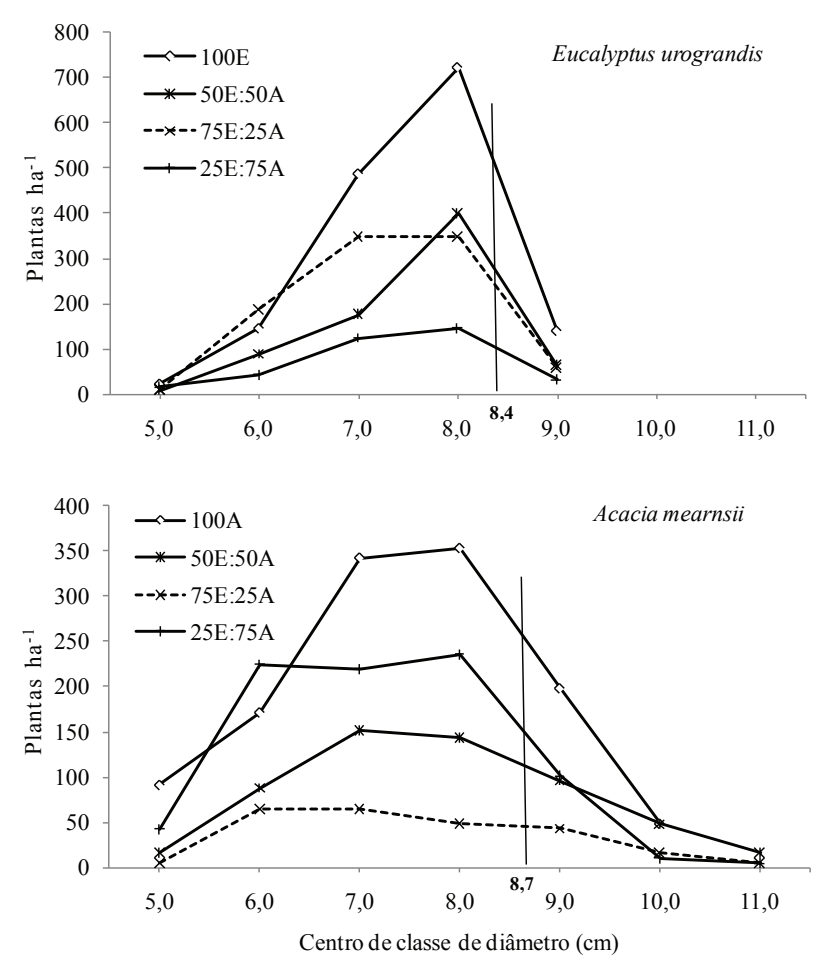

Figura 2. Distribuição diamétrica das árvores, em povoamentos monoespecíficos e mistos de Eucalyptus urograndis e Acacia mearnsii, aos 18 meses de idade (Bagé, RS, 2008/2009). 
(2008), em que o crescimento em altura total das árvores, aos 10 meses de idade, não foi influenciado pela presença ou ausência de outra espécie florestal em consórcio. Vezzani et al. (2001) também não encontraram diferença significativa no crescimento em diâmetro e altura de Eucalyptus saligna e Acacia mearnsii, entre os sistemas de cultivo, aos 45 meses de idade. Os mesmos autores salientaram que, embora o eucalipto consorciado tenha sido favorecido pelo maior suprimento de nitrogênio da acácia, esta maior disponibilidade de $\mathrm{N}$ não acarretou maior crescimento das plantas. Silva (2007), avaliando plantios monoespecíficos e mistos de Eucalyptus grandis e Acacia mangium com 29 meses de idade, também não verificou influência significativa do consórcio no crescimento em altura do eucalipto. Isto decorre, segundo o autor, da estratificação do dossel, onde as árvores de eucalipto formaram um estrato dominante e a leguminosa um estrato dominado.

Entretanto, Coêlho (2006) verificou que o crescimento em altura do Eucalyptus grandis, nos diferentes tratamentos consorciados com leguminosas arbóreas, diferiu estatisticamente apenas aos 24 meses de idade. O eucalipto consorciado com Mimosa scabrella cresceu menos. Já as demais espécies leguminosas (Acacia mangium, Inga sp., Peltophorum dubium, Acacia polyphylla e Mimosa caesalpiniaefolia) não interferiram no crescimento do eucalipto. Forrester et al. (2004) também puderam constatar a influência dos consórcios apenas a partir do segundo ano de idade do plantio, quando tanto a altura do Eucalyptus globulus como a da Acacia mearnsii aumentaram com a presença da outra espécie.

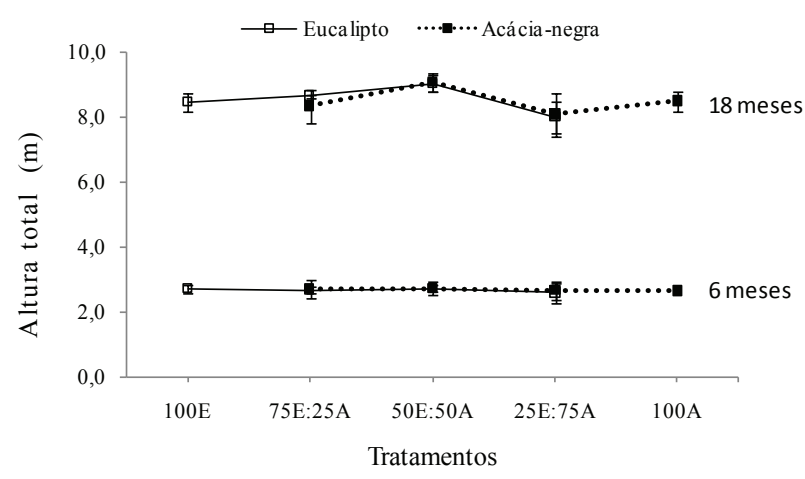

Figura 3. Crescimento em altura total (m), em povoamentos monoespecíficos e mistos de Eucalyptus urograndis e Acacia mearnsii (Bagé, RS, 2008/2009). As barras verticais correspondem ao desvio padrão da média.
O volume total de madeira com casca produzida nos plantios mistos não diferiu $(p>0,05)$ do produzido nos plantios monoespecíficos (Tabela 1). O mesmo foi verificado por Vezzani et al. (2001), com Eucalyptus saligna e Acacia mearnsii. Quanto ao índice de área foliar, pôde-se verificar aumento significativo, para o Eucalyptus urograndis em consórcio com Acacia mearnsii, indicando efeito positivo interespecífico. Hunt et al. (2006), estudando povoamentos naturais de eucalipto com presença de acácia, observaram que, durante o desenvolvimento inicial (2 a 4 anos), a Acacia dealbata e o Eucalyptus nitens apresentaram índice de área foliar similar. No entanto, aos 8 anos de idade, a acácia estava totalmente dominada, contribuindo com apenas $20 \%$ do IAF do povoamento.

Xavier et al. (2002), estudando a variação do índice de área foliar em clones de eucaliptos, ao longo do seu ciclo de desenvolvimento, encontraram valores entre 1,7 e 4,3.

Quanto maior o índice de área foliar de uma determinada espécie, menor será a incidência de radiação fotossinteticamente ativa no interior do povoamento (Fotan 2007, Cacau 2008). Dessa maneira, se for levada em consideração a utilização de plantios mistos, para a prática de agrossilvicultura, o aumento da área foliar poderia ser prejudicial ao desenvolvimento das culturas agrícolas consorciadas, mas, com a implementação de práticas silviculturais alternativas, como por exemplo, aumento de espaçamento de plantio, desramas e/ou desbastes, proporcionaria o consórcio agrícola.

A inexistência de diferenças significativas no crescimento (com exceção do índice de área foliar) e

Tabela 1. Volume de madeira com casca e índice de área foliar (IAF), em plantios monoespecíficos e mistos de Eucalyptus urograndis e Acacia mearnsii com 18 meses de idade (Bagé, RS, 2008/2009).

\begin{tabular}{ccrrrr}
\hline \multirow{2}{*}{ Tratamento } & \multicolumn{2}{c}{ Volume } & \multirow{2}{*}{$\mathrm{CV}^{(1)}$} & IAF & CV \\
\cline { 2 - 4 } & $\mathrm{m}^{3} \mathrm{ha}^{-1}$ & & & \\
\hline 100E & $34,3 \mathrm{a}^{(2)}$ & 1,2 & $3,6 \mathrm{~b}$ & 12,1 \\
100A & $34,5 \mathrm{a}$ & 17,7 & $4,0 \mathrm{~b}$ & 13,8 \\
50E:50A (E) & 16,9 & 6,2 & $5,9 \mathrm{a}$ & 16,7 \\
50E:50A (A) & 17,2 & 25,2 & $4,5 \mathrm{~b}$ & 16,2 \\
Total 50E:50A & $34,2 \mathrm{a}$ & - & - & - \\
\hline
\end{tabular}

${ }^{(1)} \mathrm{CV}=$ Coeficiente de variação. ${ }^{(2)}$ Médias seguidas pela mesma letra, na vertical, não diferem entre si pelo Teste Tukey $(5 \%)$. 
na produtividade dos plantios mistos de Eucalyptus urograndis e Acacia mearnsii deve-se, em grande parte, à juvenilidade das árvores, que possuíam apenas 18 meses de idade. Khanna (1997) e Forrester et al. (2004), avaliando plantios mistos de Eucalyptus grandis e Acacia mearnsii, verificaram a existência de diferenças significativas no crescimento apenas aos 33 e 24 meses de idade, respectivamente, dos povoamentos.

De acordo com Khanna (1997) e Vezzani et al. (2001), na fase inicial de desenvolvimento dos povoamentos (até a formação da copa), o benefício do consórcio, para o eucalipto, ocorreria pelo aumento na disponibilidade de nitrogênio no solo, essencialmente pela decomposição de raízes finas e nódulos. Após a formação da copa, a leguminosa aumentaria a taxa de ciclagem de nutrientes, devido à redução da relação C:N, no material depositado sobre o solo, estimulando a ação de micro-organismos decompositores e a consequente liberação de nutrientes.

\section{CONCLUSÃO}

O cultivo misto de eucalipto com espécies fixadoras de nitrogênio (Acacia mearnsii) apresenta uma alternativa sem perda de produtividade para o produtor florestal, visto que, até os dezoito meses de idade dos povoamentos, o crescimento e a produtividade não são influenciados negativamente pela presença de outra espécie florestal. Além disto, o silvicultor poderá obter produtos múltiplos de sua floresta, devido ao sortimento proporcionado pela presença de duas espécies florestais, sendo que o cultivo $50 \%$ eucalipto $+50 \%$ acácia-negra apresenta maior número de indivíduos com diâmetros superiores $(\mu+1$ s), em relação aos monocultivos.

\section{AGRADECIMENTOS}

Ao Conselho Nacional de Desenvolvimento Científico e Tecnológico (CNPq), pela bolsa concedida ao primeiro autor, e à empresa Votorantim Celulose e Papel, Unidade Rio Grande do Sul (atual Fibria), pela disponibilização das áreas para estudo, bem como pelo apoio logístico e financeiro.

\section{REFERÊNCIAS}

BAUHUS, J.; KHANNA, P. K.; MENDEN, N. Aboveground and belowground interactions in mixed plantations of Eucalyptus globulus and Acacia mearnsii. Canadian Journal Forestry Research, Montreal, v. 30, n. 12, p. 1886-1894, 2000.
BINKLEY, D.; GARDINA, C.; BASHKIN, M. A. Soil phosphorus pools and supply under the influence of Eucalyptus saligna and nitrogen-fixing Albizia falcataria. Forest Ecology and Management, Amsterdam, v. 128, n. 3, p. 241-247, 2000.

BINKLEY, D. et al. Twenty years of stand development in pure and mixed stands of Eucalyptus saligna and nitrogen-fixing Facaltaria moluccana. Forest Ecology and Management, Amsterdam, v. 182, n. 1/3, p. 93-102, 2003.

CACAU, F. V. Decepa de plantas jovens de eucalipto em um sistema agroflorestal: dinâmica de copa e crescimento. 2008. 47 f. Dissertação (Mestrado em Ciências Florestais)Universidade Federal de Viçosa, Viçosa, 2008.

COÊLHO, S. R. F. Crescimento e fixação de nitrogênio em plantios mistos de eucalipto e leguminosas arbóreas nativas. 2006. 55 f. Dissertação (Mestrado em Recursos Florestais: Silvicultura e Manejo Florestal)-Escola Superior de Agricultura "Luiz de Queiroz", Universidade de São Paulo, Piracicaba, 2006.

DEBELl, D. S.; COLE, T. C.; WHITESELL, C. D. Growth, development and yield of pure and mixed stands of Eucalyptus and Albizia. Forest Science, Lawrence, v. 43, n. 2, p. 286-298, 1997.

FORRESTER, D. I. et al. Effects of changing the supply of nitrogen and phosphorus on growth and interactions between Eucalyptus globulus and Acacia mearnsii in a pot trial. Plant and Soil, The Hague, v. 280, n. 1/2, p. 267277, 2006a.

FORRESTER, D. I.; BAUHUS, J.; COWIE, A. L. Carbon allocation in a mixed-species plantation of Eucalyptus globulus and Acacia mearnsii. Forest Ecology and Management, Amsterdam, v. 233, n. 2/3, p. 275-284, 2006b.

FORRESTER, D. I. et al. Mixed-species plantations of Eucalyptus with nitrogen-fixing trees: a review. Forest Ecology and Management, Amsterdam, v. 233, n. 2/3, p. 211-230, 2006c.

FORRESTER, D. I.; BAUHUS, J.; COWIE, A. L. On the success and failure of mixed species tree plantations: lessons learned from a model system of Eucalyptus globulus and Acacia mearnsii. Forest Ecology and Management, Amsterdam, v. 209, n. 1/2, p. 147-155, 2005.

FORRESTER, D. I.; BAUHUS, J.; KHANNA, P. K. Growth dynamics in a mixed-species plantation of Eucalyptus globulus and Acacia mearnsii. Forest Ecology and Management, Amsterdam, v. 193, n. 1/2, p. 81-95, 2004.

FOTAN, I. C. I. Dinâmica de copa e crescimento de clones de eucalipto submetidos a desrama em sistema agroflorestal. 2007. 68 f. Dissertação (Mestrado em Ciência Florestal)-Universidade Federal de Viçosa, Viçosa, 2007. 
GAMA-RODRIGUES, A. C. Ciclagem de nutrientes por espécies florestais em povoamentos puros e mistos, em solos tabuleiros da Bahia, Brasil. 1997. 107 f. Tese (Doutorado em Solos e Nutrição de Plantas)-Universidade Federal de Viçosa, Viçosa, 1997.

JESUS, R. M.; DIAS, G. B. N. Eucalyptus/Leucaena mixture experiment: growth and yield. Série Técnica IPEF, Piracicaba, v. 39, n. 1, p. 41-46, 1988.

HUNT, M. A. et al. Competição entre plantios de Eucalyptus nitens e a invasora Acacia dealbata no nordeste da Tasmânia. Forest Ecology and Management, Amsterdam, v. 233, n. 2/3, p. 260-274, 2006.

KHANNA, P. K. Comparison of growth and nutrition of young monocultures and mixed stands of Eucalyptus globulus and Acacia mearnsii. Forest Ecology and Management, Amsterdam, v. 94, n. 1/3, p. 105-113, 1997.

KLEINPAUL, I. S. Plantio misto de Eucalyptus urograndis e Acacia mearnsii em sistema agroflorestal. 2008. 88 f. Dissertação (Mestrado em Engenharia Florestal)Universidade Federal de Santa Maria, Santa Maria, 2008.

LACLAU, J. P. et al. Mixed-species plantations of Acacia mangium and Eucalyptus grandis in Brazil: 1. Growth dynamics and aboveground net primary production. Forest Ecology and Management, Amsterdam, v. 255, n. 12, p. 3905-3917, 2008.

MENDONÇA, A. V. R. et al. Desempenho de quatro espécies de Eucalyptus spp. em plantios puros e consorciados com sabiá (Mimosa caesalpiniaefolia Benth) em cava de extração de argila. Revista Árvore, Viçosa, v. 32, n. 3, p. 395-405, 2008.

MORENO, J. A. Clima do Rio Grande do Sul. Porto Alegre: Secretaria da Agricultura, 1961.

PARROTTA, J. A. Productivity, nutrient cycling, and succession in single- and mixed-species plantations of Casuarina equisetifolia, Eucalyptus robusta, and Leucaena leucocephala in Puerto Rico. Forest Ecology and Management, Amsterdam, v. 124, n. 1, p. 45-77, 1999.
PIOTTO, D. A meta-analysis comparing tree growth in monocultures and mixed plantations. Forest Ecology and Management, Amsterdam v. 255, n. 3/4, p. 781-786, 2008.

SCHIAVO, J. A. et al. Comportamento de Acacia mangium Wild e Eucalyptus camaldulensis, em plantio puro e consorciado, em áreas degradadas pela extração de argila no município de Campos dos Goytacazes. In: FERTIBIO, 26., 2004, Lages. Anais.... Lages: Udesc/ SBCS, 2004. 1 CD-ROM.

SILVA, E. V. Desenvolvimento de raízes finas em povoamentos monoespecificos e mistos de Eucalyptus grandis e Acacia mangium. 2007. 54 f. Dissertação (Mestrado em Recursos Florestais: Silvicultura e Manejo Florestal)-Escola Superior de Agricultura "Luiz de Queiroz”, Universidade de São Paulo, Piracicaba, 2007.

SILVA, F. de A. S. ASSISTAT versão 7.5 beta. Campina Grande: DEAG/CTRN/UFCG, 2008.

SOARES, C. P. B.; PAULA NETO, F.; SOUZA, A. L. Dendrometria e inventário florestal. Viçosa: UFV, 2006.

STRECK, E. V. et al. Solos do Rio Grande do Sul. 2. ed. Porto Alegre: Emater-RS, 2008.

UTHSCSA: image tool for Windows version 3.00. San Antonio: University of Texas Health Science Center, 2002.

VEZZANI, F. M. Aspectos nutricionais de povoamentos puros e mistos de Eucalyptus saligna (Smith) e Acacia mearnsii (De Wild.). 1997. 97 f. Dissertação (Mestrado em Ciência do Solo)-Universidade Federal do Rio Grande do Sul, Porto Alegre, 1997.

VEZZANI, F. M.; TEDESCO, M. J.; BARROS, N. F. Alterações dos nutrientes no solo e nas plantas em consórcio de eucalipto e acácia-negra. Revista Brasileira de Ciência do Solo, Viçosa, v. 25, n. 1, p. 225-231, 2001.

XAVIER, A. C.; SOARES, J. V.; ALMEIDA, A. C. Variação no índice de área foliar em clones de eucalipto ao longo de seu ciclo de crescimento. Revista Árvore, Viçosa, v. 26, n. 4, p. 421-427, 2002. 